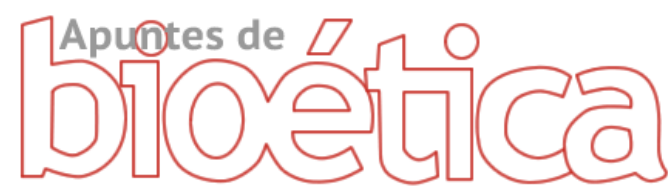

https://doi.org/10.35383/apuntes.v3i1.369

\title{
Reflexiones sobre la muerte a propósito de la pandemia
}

\author{
Onaka Nuñez J. ${ }^{1}$
}

\section{INFORMACIÓN DEL ARTÍCULO RESUMEN}

Historia del artículo:

Recibido el 25 de abril 2020

Aceptado el 29 de julio 2020

Palabras claves:
Muerte
Inmortalidad
Pandemia
Familia
Sentido del sufrimiento
Fe

$\mathrm{Fe}$

El artículo pretende suscitar una reflexión sobre la muerte a raíz de la experiencia mundial de la pandemia. La muerte siempre ha sido un tema misterioso y ha generado diversos interrogantes, pero la superficialidad en que vivimos hoy impide, en muchos casos, reflexionar sobre el tema, lo cual, sin embargo, es necesario hacer, puesto que, de la respuesta que demos depende el sentido de nuestra vida. Además, conviene estar preparados porque no sabemos cuándo vamos a morir. Se trata, pues, en este artículo, de resaltar algunos aspectos -paradójicos muchos de ellos- de la muerte, un hecho universal y necesario, aunque olvidado con frecuencia, a fin de vivirlo de una manera personal, con dignidad y esperanza, en la situación concreta de pandemia que atravesamos. Se trata, también, de resaltar el valor de los ancianos y de la familia o, en su defecto, de la amistad, en el momento del último adiós.

\section{Reflections on death from the pandemic}

\section{ABSTRACT}

\section{Keywords:}

Death

Immortality

Pandemic

Family

Sense of suffering

Faith
The article tries to provoke a reflection on death as a result of the worldwide experience of the pandemic. Death has always been a mysterious subject and has generated various questions, but the superficiality in which we live today prevents, in many cases, from reflecting on the subject, which, however, must be done, since, from the answer we give the meaning of our life depends. In addition, it is convenient to be prepared because we do not know when we are going to die. It is, therefore, in this article, to highlight some aspects -paradoxical many of them- of death, a universal and necessary fact, although often forgotten, in order to live it in a personal way, with dignity and hope, in the specific situation of pandemic that we are going through. It is also about highlighting the value of the elderly and the family or, failing that, friendship, at the time of the last goodbye.

${ }^{1}$ Máster en Ciencia de Matrimonio y Familia por la Pontificia Universita Lateranense. Docente de la Pontificia Universidad Católica del Perú, Lima Perú. Email: jonaka@gmail.com ORCID: https://orcid.org/0000-0001-6950-4555 


\section{Introducción}

Durante estos días de confinamiento obligado por la pandemia provocada por el coronavirus, hemos sido testigos de diversas reacciones y necesidades. No todo ha sido negativo, también se han dado cosas positivas, como la solidaridad, la verdadera vocación de servicio y el redescubrimiento de la importancia de la familia.

Se ha experimentado, en concreto, la necesidad de cercanía de los seres queridos en los últimos momentos de la vida, sobre todo porque, a raíz de la pandemia, muchos enfermos han tenido que morir solos. Este artículo se propone resaltar la importancia de la unidad familiar y la fortaleza espiritual que aporta en el momento de la muerte de cualquiera de los miembros. Para ello, previamente reflexionaremos sobre el tema de la muerte y las actitudes más comunes en nuestra sociedad actual.

Por lo general, ante la realidad de la muerte se pueden tener tres actitudes: evitar pensar en ella, rechazarla y darle un sentido (Pro Velasco, 2018).

¿Cuál es nuestra actitud? ¿pensamos en esta realidad última o la evadimos con todas nuestras fuerzas? ¿procuramos darle un sentido? ¿nos preparamos a morir? ¿ayudamos a otros a afrontar esta experiencia trascendental? Sin duda, es importante reflexionar sobre el inevitable fin de la vida, el aprender a vivir y a morir.

\section{Actitudes ante la muerte inevitable.}

Todos tenemos certeza de cuándo nacimos, pero no la tenemos de cuándo vamos a morir. El tema de la muerte es algo que nos interpela seriamente y tiene mucho de misterio, a pesar de que hagamos lo posible por no pensar en ello.

Podemos considerarla fríamente, desde el punto de vista biológico: Es "ley de vida", decimos. Todo lo que nace, debe morir, y, así, animales y plantas nacen, se desarrollan y mueren. Es necesaria para que siga el ciclo biológico, de otro modo, en la tierra no cabríamos. Así, racionalmente, despachamos el asunto cuando no nos afecta personalmente. Pero esta explicación racional no soluciona el problema existencial del ser humano. En realidad, la muerte es rechazable en sí misma, de ahí el inevitable rechazo.

\section{A: Rechazo de la muerte.}

Hildebrand (1983), en su libro Sobre la muerte, dice que el horror a la muerte se debe a que es un error metafísico. Es verdad que decimos, consolando a otros: "Es ley de vida", pero en realidad, la muerte es un absurdo. ¿Por qué la vida misma conlleva la muerte? ¿Por qué todo ser vivo rechaza morir, y especialmente las personas? Experimentamos la repugnancia ante la vanidad de todo. "No somos nadie", decimos, quizá sin darnos cuenta de que esto es terrible. ¿Defenderemos, como los nihilistas, que no somos nada, que todo es nada, descartable, líquido, que nada tiene solidez? Algo hay de verdad en ello: la insuficiencia de lo creado, pero no es toda la verdad. Lo veremos más adelante.

El rechazo a la muerte, sigue diciendo Hildebrand, se nos aparece, sobre todo, en dos experiencias: La muerte de los seres queridos y la muerte propia.

- En la muerte de los seres queridos nos invade la tristeza. Experimentamos la contradicción de que el mundo siga existiendo cuando la otra persona falta. Todo lo demás nos parece sin importancia. Gráficamente describe este 
sentimiento dramático san Agustín ante la muerte de un amigo:

iCon qué dolor se entenebreció mi corazón! Cuanto miraba era muerte para mí. La patria me era un suplicio, y la casa paterna un tormento insufrible, $y$ cuanto había comunicado con él se me volvía sin él crudelísimo suplicio. Buscábanle por todas partes mis ojos y no parecía. Y llegué a odiar todas las cosas, porque no le tenían ni podían decirme ya como antes, cuando venía después de una ausencia: "He aquí que ya viene" (Confesiones, IV).

- En la muerte propia -no en la conciencia racional de que "voy a morir" sino ante la inminencia de que "ivoy a morir...!"empezamos a percibir nuestro cuerpo y a sentir vivamente que estamos unidos substancialmente a él (Hildebrand, 1983); por ello nos resulta absurdo imaginar que no lo tenemos, que no podemos movernos, ni ver, ni oír... Pero no solo eso, experimentamos también el absurdo de dejarlo todo, proyectos, familia, amigos, cosas... La muerte es 'también es el fin de muchos proyectos, de las relaciones con los demás, del fin de las relaciones laborales, sociales, políticas; la muerte es la ruptura con los míos, con la comunidad, con el país" (García Amengual, 2007 , p. 440). ¿Tanto esfuerzo para nada?

De ahí el olvido y el rechazo de la idea de la muerte. Olvido, porque, aunque se sepa que vamos a morir, pocos son los que en verdad lo "saben". Vivimos como si fuéramos a vivir siempre aquí. Y rechazo, porque nos rebelamos: "¿Por qué a mí?", "Por qué a él o ella?" ¿Es este olvido y rechazo natural? ¿es bueno? Depende.

Según Redondo (2002), podemos distinguir entre un olvido y rechazo natural y un olvido y rechazo provocado y maléfico, frente a los cuales, la solución es afrontar la muerte con dignidad y esperanza, darle un sentido:

\section{Un prudente olvido y recuerdo de la muerte.}

Es natural y bueno olvidarnos y rechazar la muerte. Con la conciencia permanente de ella, sin su olvido, no podríamos vivir; sin su rechazo, tampoco, pues iríamos contra el instinto de supervivencia creado por Dios en todos los seres vivos. Así como el médico y la enfermera necesitan, en cierto modo, distanciarse del dolor de enfermos y moribundos para poder ejercer su profesión, que es rechazar la muerte, necesitamos, hasta cierto punto, olvidarnos de ella, de la propia y de la de los seres queridos, para poder vivir, y debemos rechazarla cuando amenace. Si bien es necesario también recordarla de vez en cuando, y aceptarla, cuando no haya más remedio, para vivir una vida verdaderamente humana. Quizá habituarnos a pensar, al despertarnos: "¿llegaré al final del día?" y al acostarnos: "¿Me levantaré mañana?" Si viviéramos cada día como si fuese el ultimo, cuán mejores seríamos.

Pero hay otro tipo de olvido de la muerte que no es natural ni positivo, sino provocado y maléfico:

\section{Olvido y rechazo provocado y maléfico de la muerte.}

Es el olvido del hombre moderno, de la sociedad del bienestar, consumista y hedonista, que inmortaliza el carpe diem. Había llegado a creer esta sociedad que la razón técnica lo podía todo: tener hijos artificialmente, no envejecer ni, incluso, morir -así piensa el transhumanismo-. Vivía "segura" esta sociedad con los "Seguros" de todo tipo, económicos y técnicos, y, por eso, rechazaba hablar de muerte; era un tabú, algo de mal gusto. $Y$ es así que sus seguridades se han venido abajo de repente. $Y$ es que la ciencia, 
desde la modernidad, no nos ha abierto a la realidad de las cosas, a las verdades últimas y existenciales, sino que se ha limitado a darnos un plan para dominar la realidad, controlar el sufrimiento y la muerte. Un plan ilusorio, por otra parte, de mero marketing.

Por eso ha sido una lección de realidad y de humildad la que nos ha dado este pequeño virus, el covid 19; lección que esperemos no se olvide cuando volvamos a la "normalidad".

Estas actitudes de olvido y rechazo de la muerte, artificiales y maléficas, construidas e inoculadas por la Sociedad del bienestar, no son propiamente humanas, no son realistas, y son señal y consecuencia, precisamente, de la angustia con que, inconscientemente se la teme. Son mecanismo de defensa de negación, que, si a la corta calma, a la larga, frustra.

Es preciso situarse en una actitud realista y prudente de aceptar la muerte, descubrir su sentido y afrontarla con dignidad y esperanza.

\section{Dar un sentido a la muerte. Afrontarla con dignidad y esperanza.}

¿Qué sentido puede tener la muerte? ¿No decíamos que era un absurdo metafísico? Lo sería si la muerte fuera el final, pero no lo es; la muerte es solo un paso hacia la Vida, con mayúsculas, la Vida que todos, sepámoslo o no, deseamos.

Creamos o no en la Otra vida, la muerte se presenta a todos como algo importante; en ella encontramos una grandeza que nos supera. No es cosa valadí. La muerte, por lo pronto, nos iguala a todos y relativiza lo accidental. Bien lo expresa el poeta Jorge Manrique en las Coplas a la muerte de su padre:

"Nuestras vidas son los ríos que va a dar a la mar, que es el morir.
Allí van los señoríos, dispuestos a se acabar y consumir.

Allí, los ríos caudales, allí los otros medianos e más chicos;

en llegando son iguales, los que viven por sus manos y los ricos...

¿Qué se hizo del rey D. Juan, los infantes de Aragón, ¿qué se hicieron?

¿Qué fue de tanto galán, qué de tanta invención que trujeron?

Las huestes y los torneos, paramentos, bordaduras y cimeras,

¿fueron sino devaneos? ¿qué fueron sino verdura de las eras?"

Con la muerte se nos abrirán los ojos a la verdad, terminado el "gran teatro del mundo"(Calderón de la Barca). Entonces, vacíos de cosas, de títulos, de todo, nos quedaremos solo con nuestras buenas obras; entonces, al fin, se hará justicia. "Al atardecer de la vida, te examinarán del amor" (San Juan de la Cruz, Dichos de luz y amor).

Este momento de grandeza, revelador de la verdad, no se improvisa, hay que preparar durante la vida el "acto" supremo, el de morir. Porque la muerte humana no es una simple cesación pasiva, como en los animales o plantas; no es como un corte de electricidad; es un "acto", un acto libre (Hildebrand, 1983). El que agoniza lucha, enfrenta los momentos decisivos de su vida cara a la verdad y a la eternidad. Es, especialmente entonces, persona, "protagonista"2 de sí; pone en juego todo su ser personal y responsable, ante la gran batalla final del drama de su vida. Por eso hay que ayudarle, acompañarle, $y$, aunque nos parezca que ya no nos oye, sugerirle al oído palabras de arrepentimiento y confianza en la misericordia; rezar si no podemos hacer otra cosa. "En el acto de morir -dice Hildebrand- irradia de manera especial la nobleza del hombre, fuera cual fuera la conducta de cada uno en particular" (Hildebrand,

La palabra procede del griego: "Proto" = "primer" y "agon" = "luchador" De "agon" procede "agonía", que es la última lucha del hombre, entre la vida y la muerte. 
1983, p. 56). Recordemos al Buen ladrón, a Cristo, a Sócrates, a los mártires. "Tu última obligación será la muerte y deberás afrontarla voluntaria y amorosamente" (Van Thuang, 2001) decía el gran confesor de la fe que fue el cardenal.

En el momento de la muerte "cada hombre palpa de un modo objetivo algo misterioso, grande, definitivamente serio y noble, a pesar de todo ese horror antes mencionado. Este aspecto presupone implícitamente la subsistencia del alma e incluso, de un modo indirecto, la visión sobrenatural de la muerte" (Hildebrand, p. 57).

Esta grandiosidad se refleja en el arte; en el canto gregoriano, por ejemplo, en los Requiem de importantes músicos, como Mozart; en las grandes obras de teatro, tragedias, cuadros... $\mathrm{Y}$ está ausente por completo en las palabras superficiales de la reina en Hamlet. "Ya sabes que ésta es la suerte común: todo cuanto vive ha de morir".

Entonces, que quede claro: ¿Por qué hemos de afrontar la muerte con dignidad y esperanza, con grandeza, si, como dijimos, es un absurdo?

Porque la muerte nos abre a la verdad; no es el final, sino el principio.

\section{Muerte e inmortalidad}

La muerte, queramos o no, es una realidad por la que todos tendremos que pasar, sin saber cuándo o quizá viendo su cercanía, normalmente cubierta de dolor y sufrimiento. Una reflexión de Juan Pablo II en la Carta a los Ancianos nos hace comprender este lado oscuro de la muerte:

... en la condición humana marcada por el pecado, una dimensión de oscuridad que necesariamente nos entristece y nos da miedo. En realidad, ¿cómo podría ser de otro modo? El hombre está hecho para la vida, mientras que la muerte - como la Escritura nos explica desde las primeras páginas (cf. Gn 2-3) - no estaba en el proyecto original de Dios, sino que ha entrado sutilmente a consecuencia del pecado, fruto de la "envidia del diablo" (Sb 2, 24). Se comprende entonces por qué, ante esta tenebrosa realidad, el hombre reacciona $y$ se rebela. Es significativo, en este sentido, que Jesús mismo, "probado en todo igual que nosotros, excepto en el pecado" ( $\mathrm{Hb} 4,15)$, haya tenido miedo ante la muerte: "Padre mío, si es posible, que pase de mí este cáliz" (Mt 26, 39). Y ¿cómo olvidar sus lágrimas ante la tumba del amigo Lázaro, a pesar de que se disponía a resucitarlo (cf. Jn 11, 35)? (Juan Pablo II, 1999)

Sin embargo, la fe en la eternidad nos hace esperar ese momento o vivirlo con serenidad y esperanza. La liturgia católica nos recuerda: 'Porque la vida de los que en ti creemos, Señor, no termina, se transforma; y al deshacerse nuestra morada terrenal, adquirimos una mansión eterna en el cielo" ${ }^{3}$.

La esperanza en el cielo nos da serenidad, alegría y plenitud ya en esta vida, tal como lo han testimoniado tantas personas creyentes, tal como hemos podido ver durante esta pandemia. Baste, como muestra, el testimonio de Cirillo Longo, sacerdote italiano que murió víctima del coronavirus en un hospital de Bérgamo (Italia). Antes de morir se despedía de quienes le atendían con un rosario en la mano y con los brazos en alto: "No tengan miedo porque estamos todos en manos de Dios; nos vemos en el Paraíso; recen el Santo Rosario» (Gómez Fuentes, 2020). Su fotografía tan elocuente, en la que se notaba su fortaleza de ánimo y su alegría, recorrió Italia y el mundo.

${ }^{3}$ Misal Romano, Prefacio I de difuntos. 


\section{Aprender a vivir y aprender a morir}

Normalmente todos celebramos el nacimiento de alguien y cada año celebramos también nuestro cumpleaños como una realidad nueva y grata. Sin embargo, aunque somos conscientes de que la muerte es una realidad innegable, no solemos prepararnos para ese momento decisivo y trascendental donde nos veremos cara a cara con Dios, en cuya Luz, que es Amor y Verdad, veremos nuestros actos.

Deberíamos ser más lógicos y realistas, viviendo cara a esa verdad indudable, sin aferrarnos a las cosas de esta vida, a nuestros proyectos, trabajos, dinero... Muchos viven como si no fueran a morir nunca. Tal vez por esto, caen en depresión o pierden toda ilusión ante una situación difícil, como un cáncer o una enfermedad degenerativa.

La fe nos permite vivir, de modo realista, con alegría y esperanza. Llama la atención el testimonio de Javier Mahíllo, un profesor de Filosofía español que a los 38 años asumió el diagnóstico de cáncer con serenidad y buen humor, gracias a la fe. Profesor universitario de prestigio, autor de varios libros, con muchos proyectos, casado y padre de familia, de pronto comprende que lo va a dejar todo. Empieza a escribir un libro, Vivir con cáncer, a manera de diario, sobre sus vivencias ante la inminente muerte. Se va preparando para el momento supremo, y preparando a los suyos. Este libro lo dedica a sus cuatro hijos, el mayor de once años y el pequeño de seis, como una especie de "herencia". En sus páginas se refleja la gran unidad de la familia, su amor por su esposa y sus hijos. Les dice:

Ya sé que no es gran cosa lo que os entrego como testamento. Pero al menos podréis sentiros orgullosos de haber tenido un padre que, cuando se encontró con la muerte de sopetón a los 38 años, no salió huyendo. Tengo claro que esta vida no es más que la primera parte, que, pese a pecar de humor negro, me gustaría que en mi epitafio os atrevierais a poner: Murió haciéndonos reír. (Mahíllo, 2011, p. 245)

Este testimonio nos muestra, además, que no es solo la fe en la otra vida lo que puede aportar un sentido a la muerte y al sufrimiento, lo es también el amor a las personas que nos rodean y queremos. En realidad, siempre es el amor la clave, es para lo que hemos nacido y de lo que se nos examinará al final. Por amor hacia los demás, para no hacerles sufrir, se sacan fuerzas para sufrir con garbo, para no preocuparlos en exceso.

Así pues, si nuestra actitud ante la vida es dar lo mejor de nosotros, considerando que estamos de paso y que no es esta la vida definitiva, cuando llegue la etapa final no sufriremos una experiencia traumática; será dolorosa, sí, pero llena de sentido y, por tanto, de paz. La última palabra no es 'muerte', sino 'resurrección' y "amor". Los cristianos y las personas de buena voluntad que han sabido vivir amando, han de vivir confiados en las palabras de Cristo sobre la vida eterna. Pero esta confianza se ha de extender a todos, sea cual fuere la trayectoria de su vida, pues un último acto de arrepentimiento y de amor puede suplir toda una existencia desviada.

\section{Las paradojas de la muerte}

Podría ayudar a una reflexión sobre la muerte considerar sus paradojas (García Amengual, 2007). Analizaremos algunas de ellas aplicándolas a la pandemia:

\section{a. Lo más diverso y lo más común a todos los mortales}


Lo común a todos los mortales es la muerte y la certeza de que vamos a morir. La muerte nos iguala a todos, pobres y ricos. Son cientos de miles los que han muerto durante esta pandemia, pero de muy diferentes maneras: unos muy jóvenes, cuando, al parecer, el mal no era mortal para ellos; otros, la mayoría, ancianos; algunos famosos, otros gente sencilla; para algunos el mal ha durado un par de días, para otros hasta dos meses en cuidados intensivos; la pandemia ha unido a todos los países en un mismo drama, desde el "primer" al "tercer mundo", pero ha habido diferencias en su tratamiento. Esta diversidad ante la experiencia del coronavirus ha generado interrogantes, deseos de buscar una explicación, $y$, para muchos, esta paradoja ha generado sentimientos de hermandad.

\section{b. Lo más propio del hombre y al mismo tiempo lo más extraño}

Morir es humano, pero a la vez lo consideramos lejano. En esta situación cuando se empezaron a transmitir las primeras noticias de los contagios en China, nos parecía una enfermedad y una realidad lejana; cuando llegó a Europa, parecía un poco más cercana, cuando llegó al Perú, un poco más real, pero hasta que no visita a nuestra familia no se piensa seriamente en ella. Sabemos que vamos a morir, pero no lo creemos. Así nuestra preocupación real sólo llega cuando la vemos cercana a nosotros y nuestras acciones solidarias surgen, la mayoría de las veces, cuando tocan a nuestras familias o amigos.

\section{c. Lo más cierto y lo más incierto}

Lo más cierto pues todos sabemos que vamos a morir, lo más incierto porque no sabemos cuándo será ni cómo. Las formas pueden ser muy diversas: una adolescente de 16 años falleció y no tenía enfermedades colaterales, una anciana que bordeaba los cien años fue dada de alta luego de algunas semanas de enfermedad. Otra mujer atemorizada por el Covid-19, decidió poner en práctica consejos caseros para fortalecer su sistema inmunológico y tomó baños de hierbas varias a altas temperaturas, lo cual le provocó quemaduras por vapor y murió ahogada; otros se han curado con parecidos remedios caseros. Todo esto nos lleva a confiar, no tanto en nosotros mismos cuanto en Dios, el único que realmente sabe; nos hace valorar más nuestra vida y tomarla en serio, $y$, a la vez, pensar que no somos dueños de ella.

\section{d. Lo más universal y lo más personal}

La muerte es el fenómeno más universal, pero en realidad, la soledad ante la muerte es un hecho evidente (Hildebrand, 1983). Nadie nos acompaña al morir, aunque estemos rodeados de seres queridos, nadie puede morir por mí; es una experiencia personal, única, singular, irrepetible. La actual pandemia nos presenta cada día datos estadísticos, números de muertes a nivel nacional y mundial. De acuerdo a esas cifras, pesamos que avanzamos o retrocedemos. Pero tras esas cifras hay personas concretas, cada una es singular, única; para cada una de ellas la muerte ha sido un paso trágico y único, no hay experiencias iguales. Por ello esta paradoja nos podría llevar a pensar en el valor único e irrepetible de cada persona y la importancia de nuestra ayuda en el momento de su muerte. $Y$ es aquí donde encontramos a la familia como principal protagonista.

\section{La familia y los ancianos al momento de partir}

La última reflexión podemos dedicarla a la familia y a los ancianos, a valorar ambas realidades, ya que nuestro actual ritmo de vida nos lleva a no valorarlos lo suficiente. Valorar la vida de familia, la presencia de todos sus miembros, no sólo padres e hijos sino también 
abuelos, nietos, tíos, primos, la "familia ampliada" o "familia grande" como dice el Papa Francisco (2016) en Amoris laetitia nn.187-198. Es también ahí donde nos exhorta a valorar a la presencia de los ancianos en las familias:

Así como Dios nos invita a ser sus instrumentos para escuchar la súplica de los pobres, también espera que escuchemos el grito de los ancianos. Esto interpela a las familias $y$ a las comunidades, porque «la Iglesia no puede y no quiere conformarse a una mentalidad de intolerancia, y mucho menos de indiferencia y desprecio, respecto a la vejez. Debemos despertar el sentido colectivo de gratitud, de aprecio, de hospitalidad, que hagan sentir al anciano parte viva de su comunidad. Los ancianos son hombres y mujeres, padres y madres que estuvieron antes que nosotros en el mismo camino, en nuestra misma casa, en nuestra diaria batalla por una vida digna». Por eso, «icuánto quisiera una Iglesia que desafía la cultura del descarte con la alegría desbordante de un nuevo abrazo entre los jóvenes y los ancianos!» (n. 191).

La situación actual de pandemia nos ayuda a comprender la importancia y el valor de los ancianos en nuestra vida. Debería ser una alegría cuidar, en los últimos momentos, a quienes nos han dado tanto. De hecho, es una alegría, a pesar de las dificultades y esfuerzos que entraña, y ello contrasta con la tristeza que provoca la actitud cómoda y egoísta de la cultura del bienestar y del "descarte", que quiere deshacerse de ellos.

$Y$ es que el egoísmo, lejos de generar bienestar, engendra tristeza, vacío y soledad. Así lo confirman, además de nuestra experiencia común, expertos como el psicoterapeuta Ramón Oria de Rueda: Una característica muy común en las personas infelices -afirma- es que "el egoísmo es la base de su personalidad... La gente negativa es egoísta: habla de sus problemas, de sus dificultades, de sí misma y de su mala fortuna... aunque encuentren a quien cargue con su desgracia, los egoístas son más enfermizos, más pobres y están más solos". Justo lo contrario a los más alegres, que derrochan generosidad, dice la psicóloga y experta en coach del Instituto Europeo de Psicología Positiva, Dafne Cataluña (El País, 2016). Como decía el escritor Mario Benedetti: "La generosidad es el único egoísmo legítimo. Es imposible no sentirse bien después de ayudar a alguien".

De acuerdo a los testimonios de varias personas que han visto fallecer a otros por Covid lejos de sus familias, este dolor de la separación ha sido paliado gracias a la unión familiar, unión por la que, a pesar de la distancia, se han sentido acompañados, y esto ha sido posible gracias a los medios electrónicos y a la generosidad de médicos o enfermeras que han representado a la familia, aun sin conocerla. Varios testimonios lo muestran, como por ejemplo el de la española Gemma Gallego. Cuenta que un tío suyo murió de coronavirus, tras contagiar a sus padres. La madre, superó la enfermedad, pero su padre no, murió sólo en el hospital, de la mano del médico que lo atendía. Este gesto de médico Gemma lo agradece infinito: 'Me gustaría mencionar la gran humanidad que demostró aquel doctor dándole la mano a nuestro padre para que no estuviera solo. Nunca lo olvidaremos. Gracias, Miguel" ( $A B C$ opinión, 2020). Vemos como un pequeño gesto puede ser clave en los momentos finales. $Y$ estos gestos han sido muy frecuentes en estos meses, tanto en médicos como enfermeras y resto del personal de salud. iCuántos de ellos han preparado a bien morir a estos enfermos en su soledad! La pandemia ha despertado en muchos la conciencia de acompañar al que sufre, darle una palabra de aliento o un gesto, ayudar económicamente a quien se ha quedado sin recursos. 
En Italia un médico contó cómo le había impresionado el dolor de los pacientes que ingresaban solos en el hospital y dejaban esta vida en total soledad, sin el consuelo de su familia, ni siquiera con un saludo por un medio digital. Al ver a los pacientes que no podían despedirse de sus familias, dijo: "esto me duele más que la muerte misma" (El Comercio, 2020). Pero no se quedó en lamentos, comenzó a gestionar un donativo de tablets para que las familias pudieran despedirse de sus seres queridos.

Max Fenaroli, de Bérgamo, la zona más golpeada por el Covid en Italia, cuenta que el momento más duro fue cuando a su madre, afectada por Covid, la tuvieron que llevar al hospital sola, con fiebre muy alta, respiración jadeante y muy débil. Dice:

Al mirarla, he sentido que como hijo tendría que bendecirla, pero no sabía qué decir, no tenía la fórmula, ni la oración; pero le hice la señal de la cruz, dije una oración, y después se me vino interiormente una petición: "Jesús, si todavía hay un lugar en el paraíso, acuérdate de mi madre. (El Comercio, 2020).

Este acto de fe que hizo el hijo, le ayudó a sobrellevar todo lo demás. Al día siguiente le avisaron que su madre había partido, pero tomó la noticia con mucha serenidad, sin desesperarse, pues la idea del paraíso le confortaba y le llenaba de alegría y confianza: "Ahora veo que todo esto no ha sido un tiempo perdido, sino un tiempo para crecer en la fe, en la fortaleza de la familia y en la confianza en Dios" (El Comercio, 2020).

$Y$, finalmente, nos puede ayudar la experiencia de Victor Frankl, un psiquiatra judío, discípulo de Freud, fundador de la Logoterapia y autor de varios libros de psicoterapia. Fue internado en el campo de concentración de
Auschwtiz. Como los demás prisioneros, sintió las atrocidades de los nazis, no sabía el destino final de su vida, pero cuenta que el amor que sentía por su esposa le hizo mantener la ilusión por vivir y le ayudó a soportar la dureza del campo de exterminio; señala que, a pesar de que no podía verla y ni siquiera saber si estaba viva, su amor por ella le animaba a seguir viviendo y luchando:

Mi mente se aferraba aún a la imagen de mi mujer. De pronto me asaltó una inquietud: no sabía siquiera si seguía viva. Pero estaba convencido de algo: el amor trasciende la persona física del ser amado y halla su sentido más profundo en el ser espiritual, el yo íntimo. (Frankl, 2015).

\section{Conclusiones}

- La experiencia de la pandemia nos hace palpar dos realidades innegables: una es la muerte, con toda su grandeza y seriedad, aunque la hayamos olvidado por parecernos lejana; y la otra es la familia, necesaria y querida, aunque muchas veces no la hayamos valorado lo suficiente. Constatamos que la muerte es una experiencia por la que tenemos que pasar todos y que una reflexión sobre cómo la vivimos puede ayudar en nuestro crecimiento personal.

- La muerte nos presenta diversas paradojas, las cuales se han hecho más evidentes en esta pandemia; una de ellas, que la muerte es lo más común a todos y ello nos hace sentirnos miembros de la familia universa; pero, a la vez, es lo más propio y personal, pues cada uno muere de manera singular; solo, ciertamente, pero necesitado del apoyo de quienes más queremos. También la muerte es lo más cierto y lo más incierto, pues no sabemos cuándo ni de qué manera 
moriremos. La muerte es necesaria, también lo sabemos ("ley de vida"), pero a la vez la rechazamos como un absurdo de la vida misma, que lleva en su ser su desaparición. La muerte, por otra parte, nos sugiere a gritos la inmortalidad, como aquello que la vida, la vida humana, sobre todo, el amor y la felicidad, reclaman.

- Por último, la experiencia cercana de la muerte en esta pandemia nos ha hecho reflexionar sobre estos temas, nos ha ayudado a comprender la necesidad de acompañar al otro, especialmente a los ancianos, los más afectados por el virus; nos ha hecho patente el valor de la familia en los momentos difíciles, así como la necesidad de ayudar a todos los que podamos, al menos a los cercanos. La experiencia positiva de algunos enfermos que murieron solos, pero con el consuelo del médico, aunque fuese solo con un apretón de manos, fue muy diferente de quienes no tuvieron este consuelo, lejos de la familia y de una mano amiga confortadora.

- Ante todo, la reflexión más confortadora: La muerte no es el final. Si lo fuese, ciertamente, la vida sería absurda.

\section{Bibliografía}

ABC opinión. (17 de 06 de 2020). Obtenido de Carta de dos mujeres: "El coronavirus se apoderó de nuestra familia»: https://www.abc.es/opinion/abci-gemmamaria-gallego-carta-mujeres-coronavirusapodero-nuestra-familia202006170417_noticia.html

El Comercio. (22 de 03 de 2020). Obtenido de Pacientes terminales dan el último adiós por videollamada ante coronavirus en Italia:

https://elcomercio.pe/mundo/europa/coro navirus-en-italia-pacientes-terminalesdan-el-ultimo-adios-por-videollamadaante-el-covid-19-en-milan-noticia/

El País. (13 de 10 de 2016). Obtenido de Todas las personas infelices tienen esto en común:

https://elpais.com/elpais/2016/09/29/buen avida/1475157487_598258.html

Frankl, V. (2015). El hombre en busca de sentido. Herder.

García Amengual, G. (2007). Antropología Filosófica. BAC.

Gómez Fuentes, Á. (06 de 04 de 2020). $A B C$ sociedad. Obtenido de Los curas italianos pagan un alto precio por confortar a las víctimas del coronavirus: 96 fallecidos: https://www.abc.es/sociedad/abci-curasitalianos-pagan-alto-precio-confortarvictimas-coronavirus-96-fallecidos202004061559_noticia.html

Hildebrand, D. V. (1983). Sobre la muerte. Encuentro.

Juan Pablo II. (1999). Carta a los ancianos.

Mahíllo, J. (2011). Vivir con Cáncer. Espasa Calpe.

Papa Francisco. (2016). Amoris laetitia. Obtenido de Exhortación apostólica postsinodal.

Pro Velasco, M. L. (2018). Antropología filosófica. Universidad Católica de Ávila (UCAV).

Redondo, M. L. (2002). El ineludible deseo de inmortalidad. Cuadernos de pensamiento.

Van Thuang, N. (2001). El camino de la esperanza. Edicep. 